\title{
Sennoside A Induces GLP-I Secretion Through Activation of the ERKI/2 Pathway in L-Cells
}

This article was published in the following Dove Press journal:

Diabetes, Metabolic Syndrome and Obesity: Targets and Therapy

\author{
Li Ma' \\ Xinyu $\mathrm{Cao}^{2}$ \\ Xiaotong $\mathrm{Ye}^{2}$ \\ Jianping $\mathrm{Ye} \mathbb{1}^{2}$ \\ Yongning Sun ${ }^{1,3}$ \\ 'Department of Traditional Chinese \\ Medicine, Shanghai Jiao Tong University \\ Affiliated Sixth People's Hospital, \\ Shanghai 200233, People's Republic of \\ China; ${ }^{2}$ Shanghai Diabetes Institute, \\ Shanghai Jiao Tong University Affiliated \\ Sixth People's Hospital, Shanghai 201306, \\ People's Republic of China; ${ }^{3}$ Shanghai \\ Municipal Hospital of Traditional Chinese \\ Medicine, Shanghai University of \\ Traditional Chinese Medicine, Shanghai \\ 20007I, People's Republic of China
}

Correspondence: Yongning Sun; Jianping Ye Tel +86-18930I77579; +86-138I8929364 Email ynsun2002@I26.com; yejianping@sjtu.edu.cn

\begin{abstract}
Purpose: Glucagon-like peptide-1 (GLP-1) is secreted from the intestinal L-cells to stimulate insulin secretion in the blood glucose control. Our previous study indicates that Sennoside A (SA) can increase the plasma GLP-1 level in a mouse model of type 2 diabetes. However, the mechanism of SA activity remains largely unknown. This issue was explored in this study.

Materials and Methods: $\mathrm{C} 57 \mathrm{BL} / 6$ mice were randomly divided into four groups: a control group without drug treatment, and the other groups with different SA dosages, respectively. Blood glucose was assayed by oral glucose tolerance test (OGTT). Plasma GLP-1 and insulin were investigated. Colon tissues were collected for mRNA or Western blot analysis. Immunofluorescence staining assays were performed to evaluate the number of $\beta$-cells and L-cells. In NCI-H716 cells, extracellular signal-regulated kinase 1/2 (ERK1/2) inhibitors were employed to investigate the SA-induced GLP-1 secretion mechanism.

Results: In this work, the SA was found to improve OGTT in mice. Plasma GLP-1 and insulin were markedly elevated by SA at the dosage of $45 \mathrm{mg} / \mathrm{kg} /$ day. Meanwhile, the increased phosphorylation status of EKR1/2 and prohormone convertase 1/3 ( $\mathrm{PC} 1 / 3)$ proteins were observed in the colon of SA-treated mice. The number of L-cells exhibited no change in each group. In the NCI-H716 cells, GLP-1 secretion induced by SA was blocked by the ERK1/2 inhibitor.

Conclusion: The present study provides a direct evidence for the interaction between SA and $L$ cells for induction of GLP-1 secretion. These data suggest that GLP-1 secretion induced by SA is dependent on the ERK1/2 signaling pathway. Therefore, the SA is a new drug candidate for the type 2 diabetes treatment by induction of GLP-1 secretion.
\end{abstract}

Keywords: Sennoside A, glucagon-like peptide, 1, GLP, 1, extracellular signal-regulated kinases 1/2, ERK1/2, L-cells, prohormone convertase 1/3, PC1/3

\section{Introduction}

Glucagon-like peptide-1 (GLP-1) is encoded by the proglucagon (GCG) gene in the intestinal L cells. GLP-1 secretion is induced by nutrients in the control of blood glucose and food intake. ${ }^{1}$ GLP-1 decreases blood glucose through multiple mechanisms, which includes the promotion of glucose-induced insulin secretion from the pancreatic $\beta$ cells. It was reported that the decrease of GLP-1 was involved in the pathogenesis of type 2 diabetes (T2DM). ${ }^{2-4}$ The induction of GLP-1 activity is an effective strategy in the treatment of T2DM for various GLP-1 analogous. The GCG gene encodes the hormone glucagon in the pancreatic $\alpha$-cells, a hormone elevated in the fasting condition for the induction of gluconeogenesis. The GCG gene products, GLP-1 and glucagon, are derived from alternative RNA posttranslational processing of prohormone by convertase $\mathrm{PC} 1 / 3$ in L-cells, and convertase PC2 in $\alpha$-cells, respectively. ${ }^{5}$ The active form of GLP-1 (7-36 amide) is degraded 
into an inactive form (9-36 amide) by Dipeptidyl peptidase-4 (DPP4). ${ }^{6,7}$ The active form of GLP-1 is essential in the control of blood glucose. ${ }^{8,9}$

Sennoside A (SA), a major active constituent of Rhei Rhizoma, has been widely used in the treatment of constipation. SA activity was reported in the reduction of energy absorption through an acceleration of intestine transmits. ${ }^{10,11}$ It is reported that SA can restore GLP-1 level in the dietinduced obese (DIO) mice by an improvement of the gut microbiota profile, the short-chain fatty acids (SCFAs) levels, the mucosal structure and mitochondrial function in the colon of obese mice. ${ }^{12}$ Also, SA improved hepatic steatosis with a beneficial effect on mitochondrial structure and function. ${ }^{13}$ These studies demonstrate that SA may control obesity by means of the restoration of GLP-1 level in the obese mice. However, the mechanism of SA activity remains to be characterized in the regulation of GLP-1. The pharmacokinetic study showed that SA has a very low ability to enter the bloodstream. ${ }^{14}$ Therefore, it seems unlikely that SA works through the blood circulation.

In this work, SA activity was investigated in normal mice through examining body weight, oral glucose tolerance test (OGTT), plasma GLP-1 level and insulin level. Several signal molecules were studied, which included the phosphorylation status of extracellular signal-regulated kinases $1 / 2(E R K 1 / 2)$ and the protein expression of PC1/ 3. In the NCI-H716 cells, ERK1/2 inhibitor (PD98059) was employed to test the role of ERK1/2 pathway for clarifying the SA-induced GLP-1 secretion mechanism.

\section{Materials and Methods}

\section{Chemicals and Reagents}

Sennoside A ( $98 \%$ in purity) was purchased from Desite biotechnology CO. Ltd. (Chengdu, China). The antibodies to GCG (ab200474, Abcam), PC1/3 (ab220363, Abcam), pERK1/2 (Thr202/Tyr204) (4370T, Cell Signaling Technology), ERK1/2 (4370S, Cell Signaling Technology) were obtained from the China Divisions of the corresponding companies. The ERK1/2 inhibitor PD98059 was got from MCE (HY-12,028, shanghai, China). Other chemicals were purchased from Sigma-Aldrich Co. Ltd. (Shanghai, China) unless stated otherwise.

\section{Animals}

Male C57BL/6 mice (6-week-old, SPF grade) were purchased from the Shanghai Xipuer-Bikai Laboratory Animal Co. Ltd. (Shanghai, China). The mice were kept in the animal facility of Shanghai Jiao tong University with controlled temperature $\left(22 \pm 2{ }^{\circ} \mathrm{C}\right)$, humidity $(60 \pm 5 \%)$ and a 12 -h dark/light cycle. They were fed on a standard chow diet $(13.5 \% \mathrm{Kcal}$ from fat, Shanghai Slac Laboratory Animal Co. Ltd) in the study. The mice were randomly divided into four groups at $n=12$. Group one was employed for a control group without drug treatment. The other three groups were treated with Sennoside A (SA) by three dosages: a low dose $(15 \mathrm{mg} / \mathrm{kg} /$ day $)$, medium dose (30 $\mathrm{mg} / \mathrm{kg} /$ day) or high dose $(45 \mathrm{mg} / \mathrm{kg} /$ day). SA was delivered to the mice through drinking water. The treatment was implemented for five weeks. At the end of treatment, the mice were subjected to tissue collection under the anesthesia following an intraperitoneal injection of sodium pentobarbital $(35 \mathrm{mg} / \mathrm{kg})$. The procedures were approved by the Institutional Animal Care and Use Committee (IACUC) of the Shanghai Jiao tong University in accordance with the Guidelines for the Care and Use of Laboratory Animals (DWSY2014-068/ DWLL2019-0275).

\section{Oral Glucose Tolerance Test (OGTT), Plasma GLP-I and Insulin Assay}

OGTT was executed with overnight (12 h) fasting at a week before the mice was sacrificed. Glucose was administrated for the mice at $2 \mathrm{~g} / \mathrm{kg}$ body weight by oral gavage in the OGTT assay. Plasma GLP-1 was determined in the mice through the ocular vein blood collected with heparin tubes containing dipeptidyl peptidase IV inhibitor $(10 \mu \mathrm{L} / \mathrm{mL})$, which was executed at 15 mins after oral administration of glucose. The plasma was obtained by centrifugation of the blood at 3000 $\mathrm{g}$ and stored at $-80^{\circ} \mathrm{C}$ before the GLP-1 assay. Plasma GLP-1 and insulin were determined individually using the corresponding ELISA kits according to the manufacturer's instructions. The biologically active form of GLP-1 (7-36) and insulin were measured with the GLP-1 ELISA Kit (BMS2194, Invitrogen, CA, USA) and insulin ELISA Kit (90,080, Crystal Chem, Downers Grove, USA).

\section{Immunofluorescence Stainings}

In the tissue collection, the proximal colon was excised, washed with ice-cold saline, and stored at $-80{ }^{\circ} \mathrm{C}$. Pancreas and colon tissues were collected and fixed in $4 \%$ paraformaldehyde for analysis of $\beta$-cells and L-cells with immunofluorescence assays. The antibody-based staining was performed to determine the numbers of $\mathrm{L}$ cells in the colonic tissue and $\beta$-cells in the pancreas. Briefly, the tissue slides were deparaffinized, rehydrated, and experienced antigen retrieval with EDTA $(\mathrm{pH} 9.0)$. 
The slides were preincubated with $0.5 \%$ bovine serum albumin (BSA) to block the nonspecific interaction between antibody and samples. The GLP-1 antibody (diluted 1:800, Servicebio, Shanghai, China) and the insulin antibody (diluted 1:200, Servicebio, Shanghai, China) were applied to the slide for overnight at $4{ }^{\circ} \mathrm{C}$, respectively. The slides were incubated with a secondary antibody (diluted 1:400, Servicebio, Shanghai, China) at room temperature for 50 mins after washing out the first antibody. The nuclei were stained with DAPI for 10 mins at room temperature to evaluate the cell density. The fluorescent images were captured under a fluorescent microscope (Olympus, Tokyo, Japan).

\section{Cell Culture}

Human NCI-H716 cells were obtained from the Cell Bank of the China Science Academy (Shanghai, China). The cells grew in suspension at $37.8{ }^{\circ} \mathrm{C}, 5 \% \mathrm{CO}_{2}$. The culture medium was RPMI 1640 (11,875-093, Gibco, USA) supplemented with $10 \%$ FBS, $2 \mathrm{mM}$ L-glutamine, $100 \mathrm{IU} / \mathrm{mL}$ penicillin, and $100 \mathrm{mg} / \mathrm{mL}$ streptomycin. Cell adhesion and differentiation were induced by seeding the cells in dishes coated with Matrigel in high-glucose DMEM, 10\% FBS, $2 \mathrm{mM} \mathrm{L}$-glutamine, $100 \mathrm{IU} / \mathrm{mL}$ penicillin, and $100 \mathrm{mg} / \mathrm{mL}$ streptomycin as shown in a previous study. ${ }^{15}$

\section{Cell Viability Assay by CCK 8}

NCI-H716 cells $\left(5.0 \times 10^{4}\right)$ were seeded in a 96-well culture plate to induce cell differentiation for two days before the GLP1 experiments. When the cells grew to $80 \%$ confluence, the culture medium was replaced with a serum-free DMEM supplemented with $0.2 \% \mathrm{BSA}$, and the cells were treated with SA at different concentrations for $24 \mathrm{~h}$ in the medium. Cell viability was measured using the cell counting kit - CCK8 assay Kit (Dojindo, Japan) ( $n=6 /$ group). The percentage of living cells was calculated, which were described in this research. ${ }^{16}$

\section{GLP-I Secretion in NCl-H7l6 Cells}

The NCI-H716 cells $\left(5.0 \times 10^{5} /\right.$ well $)$ were seeded in a 24 well culture plate to induce cell differentiation. On the day of the experiment, medium was replaced with the KrebsRinger bicarbonate buffer (KRB, $128 \mathrm{mmol} / \mathrm{L} \mathrm{NaCl}, 4.8$ $\mathrm{mM} \mathrm{KCl}, 2.5 \mathrm{mM} \mathrm{CaCl}_{2}, 1.2 \mathrm{mM} \mathrm{MgSO} 4,1.2 \mathrm{mM} \mathrm{KH}_{2}$ $\mathrm{PO}_{4}, 5 \mathrm{mM} \mathrm{NaHCO} 3$, and $10 \mathrm{mM}$ HEPES, pH 7.4) containing $0.2 \%$ BSA and different concentrations of SA ( 0 $\mu \mathrm{M}, 1 \mu \mathrm{M}, 10 \mu \mathrm{M}$ or $100 \mu \mathrm{M})$ in the presence of $1 \mathrm{mM}$ diprotin A. Following incubation at $37.8{ }^{\circ} \mathrm{C}$ for $2 \mathrm{~h}$, the supernatants were collected, treated with $50 \mathrm{mg} / \mathrm{mL}$ phenylmethylsulphonyl fluoride, and stored at $-80{ }^{\circ} \mathrm{C}$ for analysis of GLP-1 with the ELISA kit. In the study of the ERK pathway, NCI-H716 cells were pretreated with ERK1/2 inhibitors (PD98059, $50 \mu \mathrm{M}$ ) for $30 \mathrm{~min}$ in the presence of SA $(100 \mu \mathrm{M})$. The cells were harvested by scraping, and the protein content of the cells was determined by the enhanced BCA protein assay kit. The GLP-1 content was normalized for the total protein of the cells.

\section{mRNA of GLP-I}

Total RNA was extracted from the colon tissues using TRIzol reagent (Invitrogen Life Technologies, CA, USA), and cDNAs were generated using a first-strand cDNA synthesis kit (Takara, Tokyo, Japan). The qRTPCR was performed, which was described in detail. ${ }^{17}$ The primers of GLP-1 were listed below: GLP-1 forward, 5'-GAGGACCCTGATGAGATGAATG-3'; and reverse, 5'-GGAGTCCAGGTATTTGCTGTAG-3'.

\section{Statistical Analysis}

The results are expressed as the mean $\pm \mathrm{SEM}$ to indicate the magnitude of the potential error when using existing samples in this study to infer the population. The statistical analyses were performed using one-way ANOVA. Tukey's test for post-hoc analysis is performed after one-way ANOVA when there are significant differences between groups. All statistical analyses were performed using GraphPad Prism 8.0 (La Jolla, CA, USA) with a statistical significance set at $P<0.05$.

\section{Results}

\section{Sennoside A Improved OGTT in Mice}

C57BL/6 mice were fed on Chow diet and treated with SA for 5 week at 3 dosages $(15,30$, and $45 \mathrm{mg} / \mathrm{kg} / \mathrm{day})$ through the drinking water. The body weight markedly decreased in the group of $45 \mathrm{mg} / \mathrm{kg} /$ day compared with the untreated mice in the control group (Figure 1A). OGTT was conducted in the mice to test the influence of SA on GLP-1. Oral intake of glucose induces the GLP-1 secretion in the intestine. In OGTT, the blood glucose did not exhibit a important change at the basal condition in all groups of mice. The blood glucose significantly reduced in the mice of $45 \mathrm{mg} / \mathrm{kg} /$ day group after 15 mins of oral glucose administration. The glucose level was lower in the group at 30 mins and 60 mins than the control group (Figure 1B). No obvious change was observed for SA at the low or medium dosages (Figure 1B). 
A

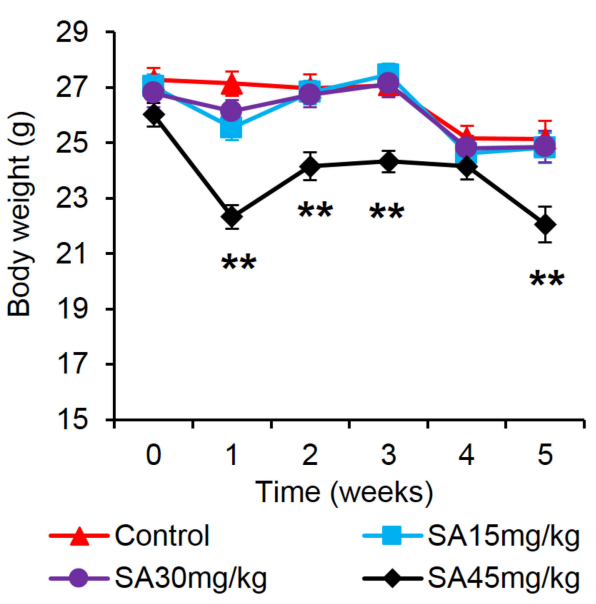

B

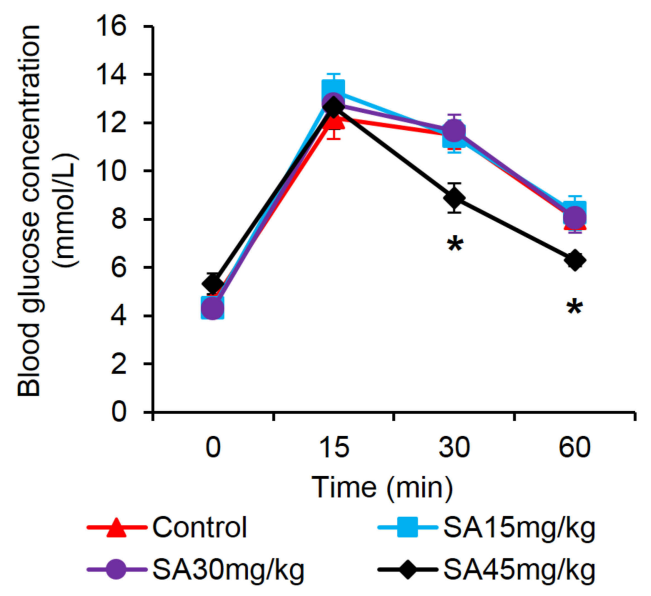

Figure I Sennoside A treatment improved OGTT. (A) Bodyweight. (B) Blood glucose at $t=0 \mathrm{~min}, 15 \mathrm{~min}, 30 \mathrm{~min}$, and $60 \mathrm{~min}$ after the glucose load. Data are presented as the mean \pm SEM; $n=12$. $* P<0.05$ vs the normal control group. $* * P<0.01$ vs the normal control group.

\section{Sennoside A Induced Plasma GLP-I}

The plasma GLP-1 was examined in the mice to investigate the mechanism of improved OGTT by SA. The improvement of OGTT means that SA may promote the GLP-1 secretion in the lean mice. Blood GLP-1 was determined in the plasma at 15 mins of oral glucose challenge, which was often used to measure the GLP-1 secretion. GLP-1 showed a trend of upregulation in the mice treated with $\mathrm{SA}$, and the increase was in a dose-dependent manner (Figure 2A). An increase was displayed in the SA-treated group at dosage of $45 \mathrm{mg} / \mathrm{kg} /$ day (Figure 2A). The number of L-cells was examined in the large intestine for the mechanism of GLP-1 induction by SA with immunofluorescence staining against GLP-1. No apparent change was observed in the SA-treated groups as indicated by the mean value of optical density (MOD) of fluorescence (Figure 2B). The GCG protein was studied in the homogenization of large intestine, and no alteration was observed in the SA-treated group (Figure 2C). There was no alteration in GLP$1 \mathrm{mRNA}$ in the large intestine of SA-treated mice (Figure 2D).

\section{Sennoside A Induced Plasma Insulin}

Plasma insulin was investigated in the mice to evaluate the GLP-1 function. An evidently increase was found in the plasma insulin in the group of $45 \mathrm{mg} / \mathrm{kg} /$ day (Figure 3A). To further analyze the number of islet $\beta$ cells, the insulin immunofluorescence staining in mouse pancreatic tissue was performed. The number of $\beta$-cells increased in the pancreatic islet in the group of $45 \mathrm{mg} / \mathrm{kg} /$ day (Figure 3B and C). The increase in the biological activity of GLP-1 was supported by the assessment of plasma insulin and $\beta$-cell numbers.

\section{Sennoside A Induced Activation of ERKI/ 2 Pathway and Expression of $\mathrm{PCI} / 3$ in Colon Tissue}

GLP-1 produced from PC1/3-mediated cleavage of proglucagon protein. The activity of $\mathrm{PC} 1 / 3$ was explored with its protein abundance. An obvious increase in $\mathrm{PC} 1 / 3$ protein was found in the colon of the SA-treated group (Figure 4A). In the research on the signaling pathway of SA in the induction of GLP-1 secretion, several signaling molecules were studied. An increase in ERK1/2 activity was observed with the change in phosphorylation status in the SA-treated mice (Figure 4B). The results indicate that SA may increase ERK1/ 2 activity in the intestinal L-cells to induce GLP-1 secretion.

\section{Sennoside A Induced GLP-I Secretion in $\mathrm{NCl}-\mathrm{H} 7 \mathrm{I} 6$ Cells}

To ascertain the active role of SA in the inducing GLP-1, the cellular model of GLP-1 secretion was used. In the NCIH716 cells, GLP-1 secretion was induced by SA in the culture supernatant, and a significant increase was found at the dosage of $1 \mu \mathrm{M}$ and above of SA (Figure 5A). SA did not display any toxicity in the cell model for no reduction in the cell viability (Figure 5B), which was examined with the CCK8 assay in the $24 \mathrm{~h} \mathrm{SA-treatment.} \mathrm{The} \mathrm{protein} \mathrm{level} \mathrm{of}$ GCG did not increased in the SA-treated cells (Figure 5C), which demonstrated that the SA did not induce GLP-1 expression in the cells. The $\mathrm{PC} 1 / 3$ expression was induced by SA in the cells (Figure 5D), which was in consistent with the intravital experiments. 
A

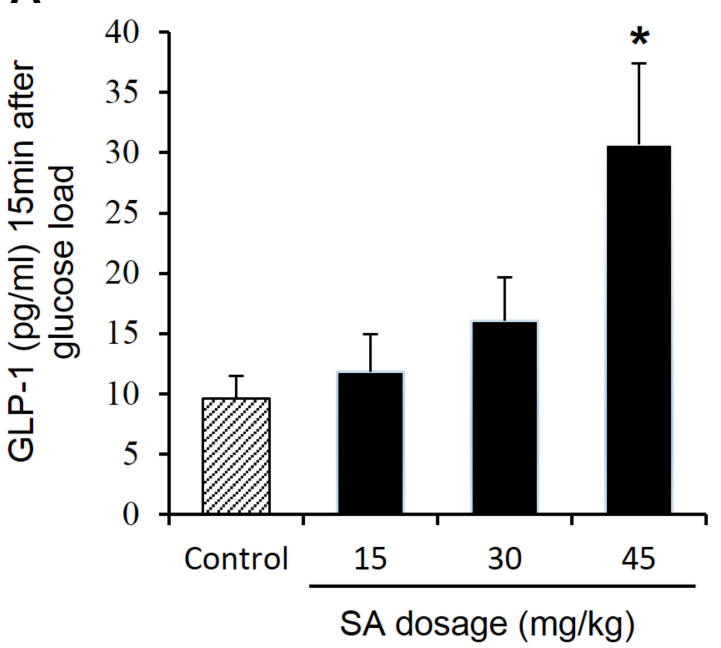

C

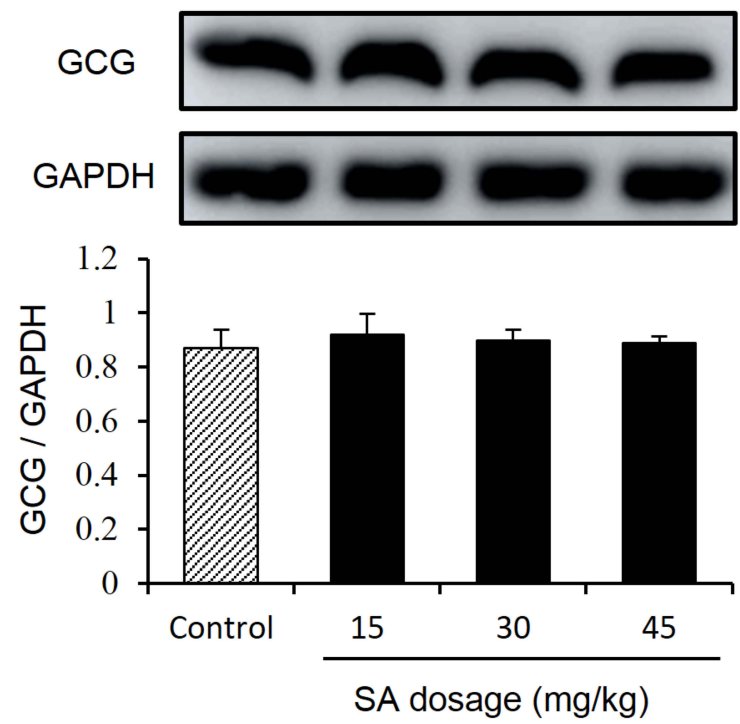

B

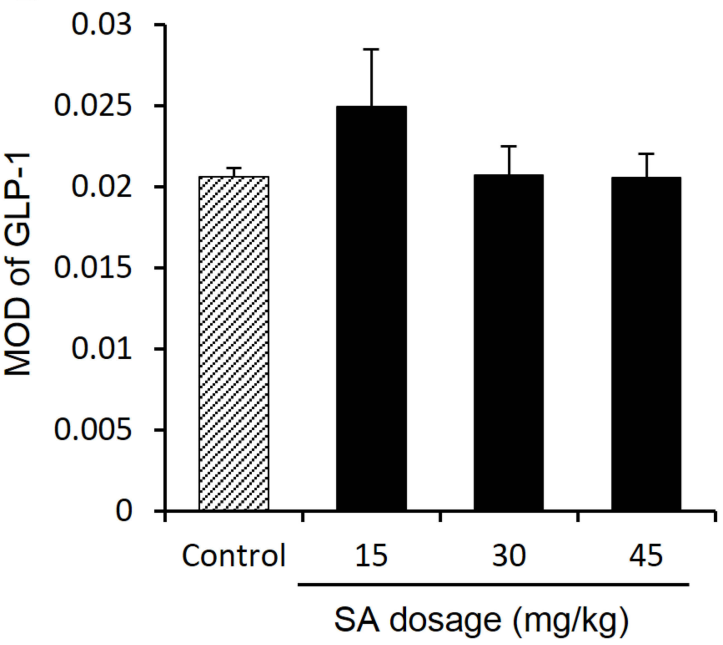

D

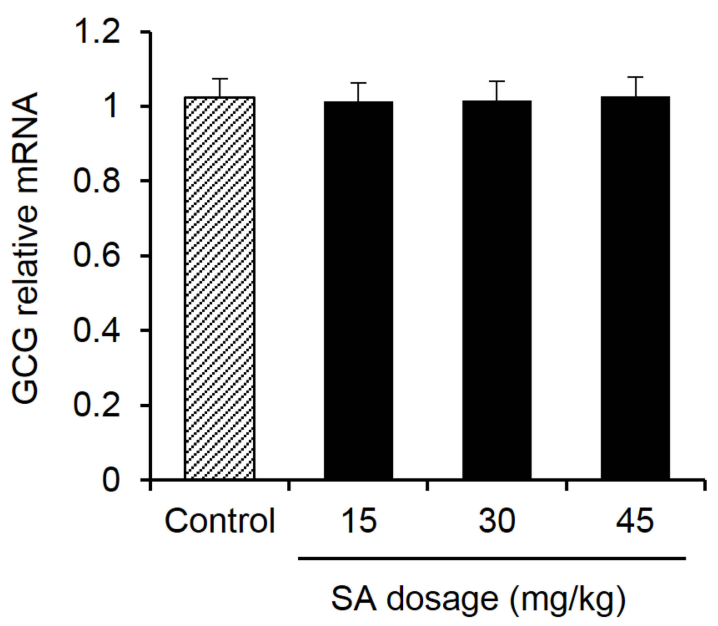

Figure 2 Sennoside A induced plasma GLP-I. (A) Plasma GLP-I. (B) L-cell number: evaluation of mean optical density (MOD) in the GLP-I immunofluorescence staining for different groups. (C) The expression of GLP-I progenitor (GCG) in the colon tissue. (D) mRNA expression of GLP-I in the colon tissue. Data are presented as the mean \pm SEM; $n=10$. $* P<0.05$ vs the normal control group.

\section{Sennoside A-Induced GLP-I Secretion Is Blocked by ERKI/2 Inhibitor (PD98059)}

The above data suggested the protein level of GCG and L cell number did not increased in the SA-treated cells. To confirm the mechanism of SA-induced GLP-1 secretion, the protein expression of ERK1/2 by Western blot analysis was investigated in NCI-H716 cells. Similar to the findings in the vivo experiments, the protein expression of ERK1/2 phosphorylation significantly increased in the $2 \mathrm{~h}$ SA-treatment (Figure 6A). The in vivo and in vitro experiments showed that the ERK1/2 signaling pathway played an important role in SA-regulated GLP-1 secretion. To test the possibility, the NCIH716 cells were pretreated for 30 min with media containing ERK1/2 inhibitor (PD98059, 50 $\mu \mathrm{M})$ in the presence of SA
$100 \mu \mathrm{M}$. It was shown that the sole PD98059 did not affect the GLP-1 secretion compared with control (Figure 6B). However, the elevation of GLP-1 levels induced by SA was abolished by preincubation with PD98059 (Figure 6B). The data suggested that SA induced GLP-1 secretion from L-cells in an ERK1/2-dependent manner.

\section{Discussion}

This study demonstrates that SA may induce GLP-1 secretion through a direct interaction with L-cells. SA is a single compound derived from Chinese herbal medicine such as Rhei Rhizoma. SA is believed to reduce adiposity through inhibition of nutrient absorption in the intestine through the stimulation of intestine transition, which 
A

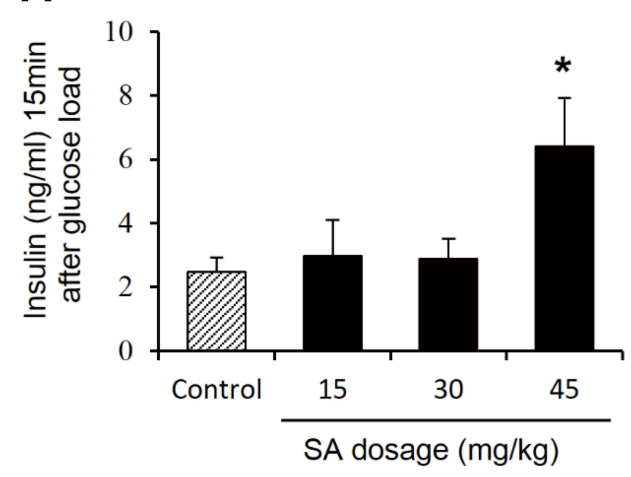

C

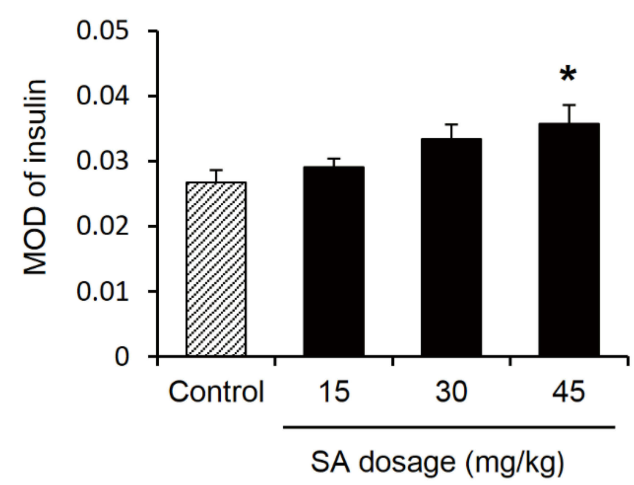

B

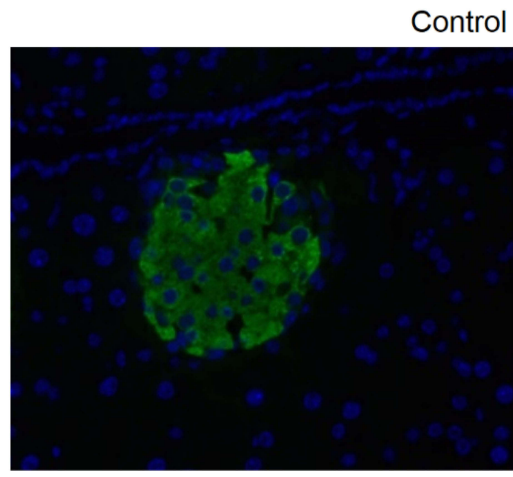

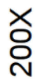

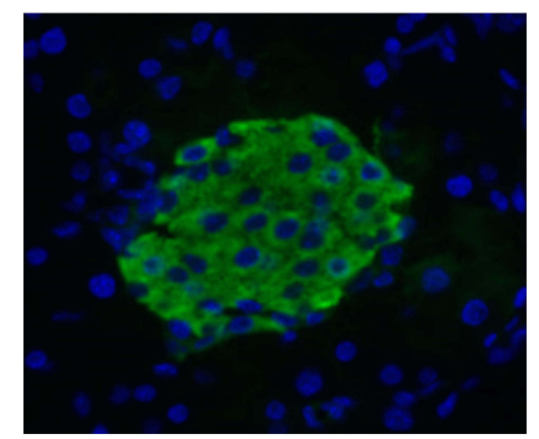

Figure 3 Sennoside A induced plasma insulin. (A) Plasma insulin. (B) Islet size by immunofluorescence staining with insulin (green). Nuclei were stained with DAPI (blue). (C) Evaluation of $\beta$ cell number: Mean optical density (MOD) of insulin. Data are presented as the mean $\pm S E M ; n=6$. ${ }^{*} P<0.05$ vs the normal control group.

A
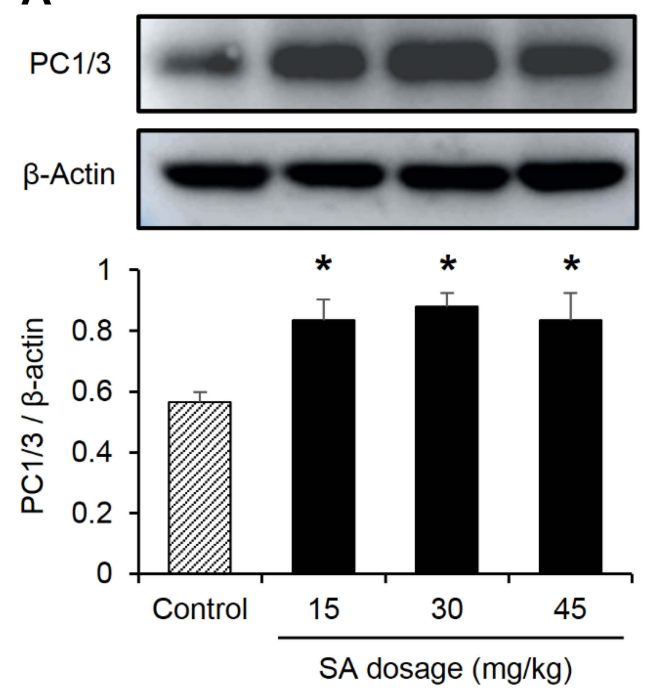

B pERK1/2

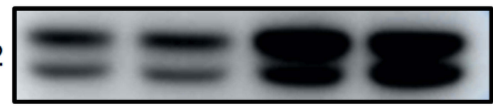

ERK1/2
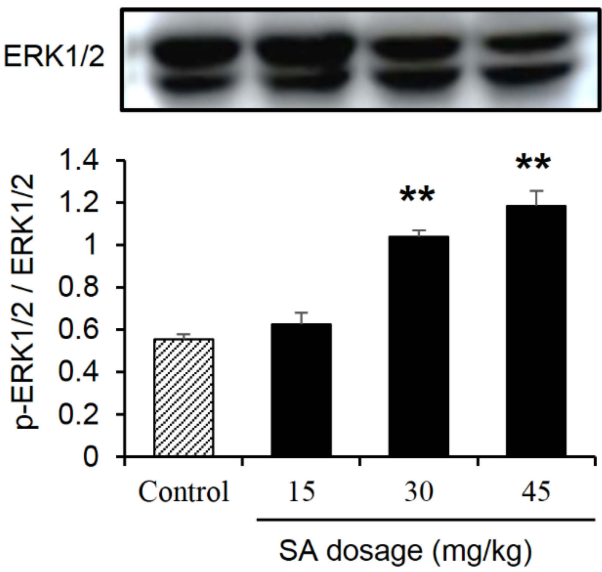

Figure 4 Sennoside $A$ induced activation of ERKI/2 pathway and expression of $\mathrm{PCl} / 3$ in colon tissue. (A) The PCl/3 expression influenced by SA in the colon of normal mice. (B) ERKI/2 expression influenced by SA in the colon of normal mice. Data are presented as the mean $\pm \mathrm{SEM} ; \mathrm{n}=6$. $* P<0.05 \mathrm{vs}$ the normal control group. $* * P<0.0 \mathrm{I}$. vs the normal control group.

decreases the time of food digestion and nutrient absorption in the intestine. The influence of SA in GLP-1 was observed in obese mice in our earlier studies. ${ }^{12}$ Nevertheless, the SA activity remains to be characterized in the regulation of GLP-1 secretion, especially a direct effect of SA on L-cells. In the current study, SA was found to directly stimulate L-cells in the intestine to induce GLP1 secretion with an improvement of OGTT in the nonobese 
A

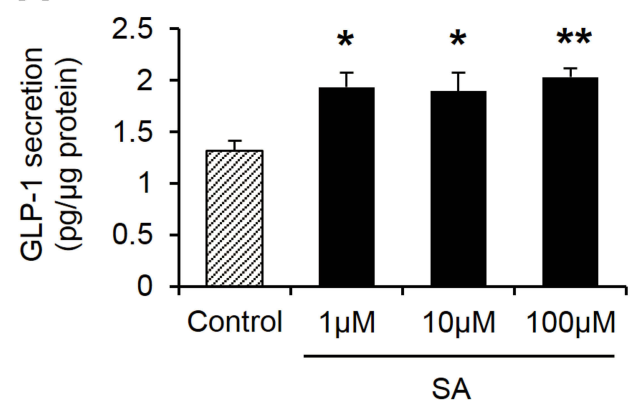

C
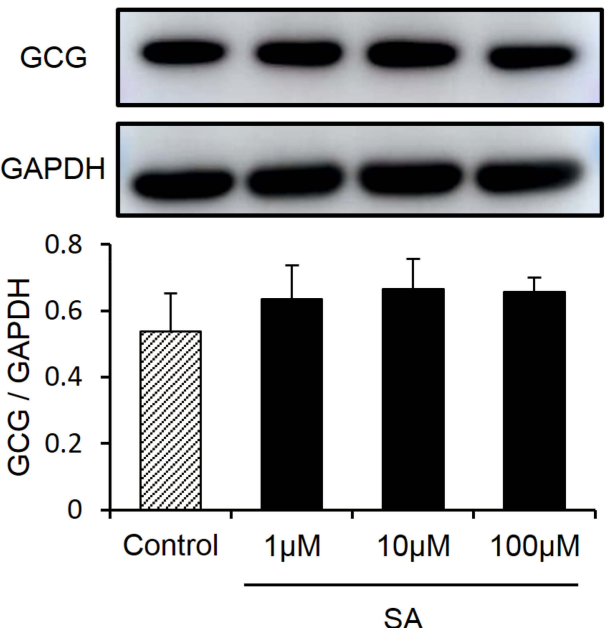

B

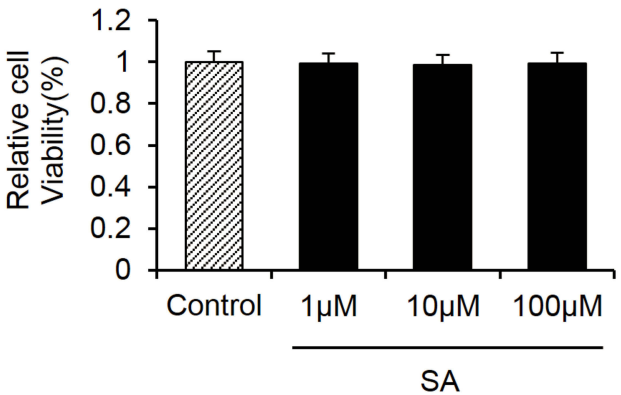

D

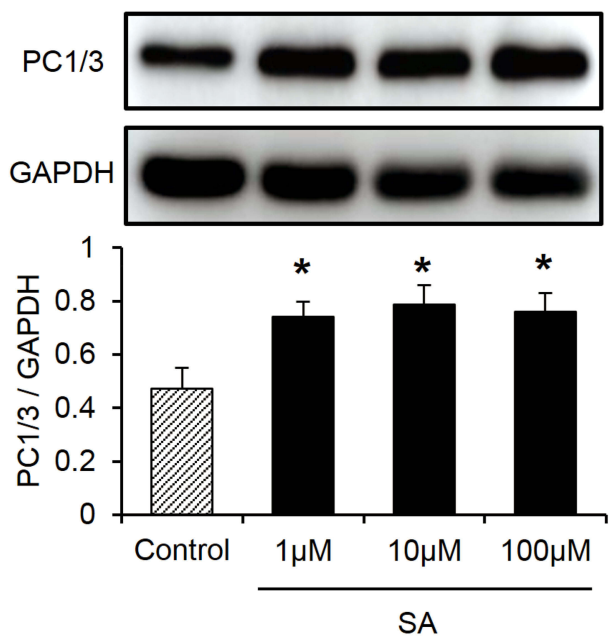

Figure 5 Sennoside A induced GLP-I secretion in NCl-H7I6 cells. (A) GLP-I levels treated by different concentrations of SA in NCl-H7I6 cells. (B) Cell viability assay by CCK8. (C, D) GLP-I progenitor, $\mathrm{PCl} / 3$ expression influenced by SA in $\mathrm{NCl}-\mathrm{H} 7 \mathrm{I} 6$ cells. Data are presented as the mean $\pm \mathrm{SEM} ; \mathrm{n}=6$. $* \mathrm{P}<0.05$ vs the normal control group. $* * P<0.01$. vs the normal control group.

A
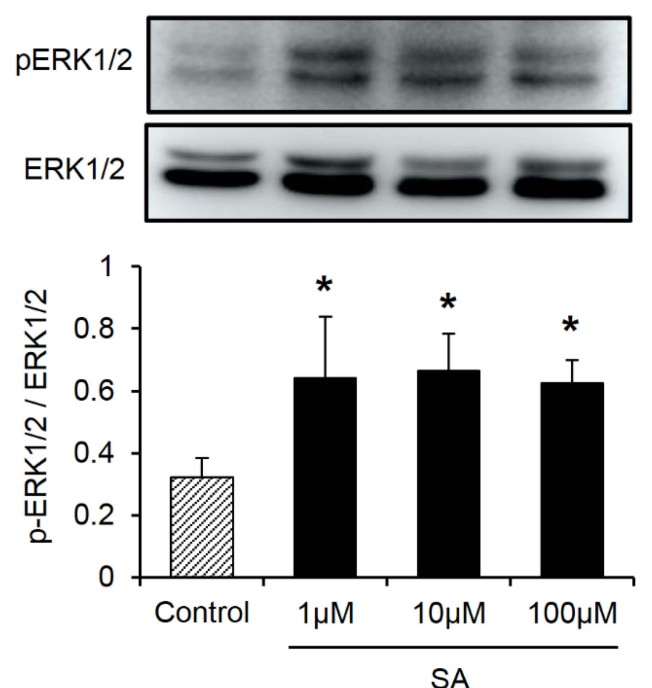

B

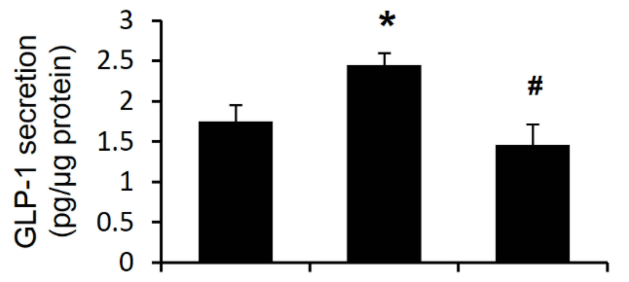

pERK $1 / 2$

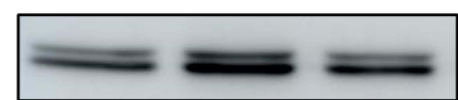

ERK1/2

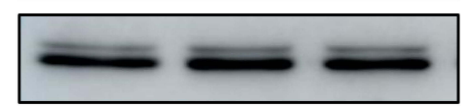

SA $100 \mu \mathrm{M}$

PD98059 $(50 \mu \mathrm{M})$

Figure 6 Sennoside A-induced GLP-I secretion is blocked by ERKI/2 inhibitors (PD98059). (A) ERKI/2 expression influenced by SA in NCI-H7I6 cells. (B) Effect of ERKI/ 2 inhibitor (PD98059) on GLP-I. Data are presented as the mean \pm SEM; $n=6$. ${ }^{*} P<0.05$ vs the normal control group. ${ }^{\#} P<0.05$. vs the SAI00 $\mu M$ group.

mice. SA do not change the L-cell density in the large intestine, which supports that other mechanisms may be implicated in the increase of plasma GLP-1 levels by SA.
Since the SA is not absorbed into the blood, it is unlikely that SA acts on L-cells through the blood circulation. SA increased the production of short-chain fatty acids 
(SCFAs) in the obese mice by the impact on gut microbiota. $^{12}$ It is reported that the SCFAs can induce GLP-1 secretion. ${ }^{18}$ However, the cell culture data of the current study demonstrated that SA might act on L-cells directly without the involvement of SCFAs, which suggested that the increased level of plasma GLP-1 in the SAtreated mice was attributed to an enhanced secretion of L-cells upon SA stimulation. The influence of SA was observed at $45 \mathrm{mg} / \mathrm{kg} / \mathrm{day}$. The elevated GLP-1 was found with the enhanced $\beta$-cell function in insulin secretion and an increased number of $\beta$-cells in the pancreatic islet, which supported the increase in the biological activity of GLP-1.

The present data indicate that the SA may act through induction of protein abundance of PC1/3 in the L-cells. PC1/3 promotes the GLP-1 secretion by the processing of the proglucagon peptide. The SA effect on the $\mathrm{PC} 1 / 3$ was observed in the intestine tissue of SA-treated mice. The influence was confirmed in NCI-H716 cells, which showed that the direct interaction between SA and L-cells led to the $\mathrm{PC} 1 / 3$ elevation. The up-regulation of $\mathrm{PC} 1 / 3$ protein abundance by SA provides a molecular mechanism for the SA activity in the induction of GLP-1 secretion.

This work also suggests that the ERK1/2 pathway may mediate the SA activity in the induction of GLP-1 secretion. The ERK1/2 pathway involves in the cell growth, development, proliferation, and differentiation. ${ }^{19}$ ERK1/2 participates in the various physiological and pathological processes through the regulation of a variety of downstream molecules. ${ }^{20,21}$ Insulin was reported to induce GLP-1 secretion by the activation of ERK1/2 in NCIH716 cells. An impairment of ERK1/2 activity made the cells secrete less GLP-1 upon insulin stimulation. ${ }^{22}$ SCFA also stimulated GLP-1 secretion via the GPR43, and GPR43 was also linked to activation of ERK1/2. ${ }^{18,23}$ In this study, the ERK1/2 activity was induced by SA, and the induction of GLP-1 secretion by SA was blocked by inhibition of ERK1/2. It is not clear that whether ERK1/2 is involved in the regulation of $\mathrm{PC} 1 / 3$.

It was reported that the cAMP-activating agents forskolin and IBMX promoted the GLP-1 secretion, suggesting that the cAMP/PKA signaling pathway may participate in the regulation of GLP-1 release. ${ }^{24}$ Additionally, an increase in the cytosolic $\mathrm{Ca}^{2+}$ concentration was another mechanism for the GLP-1 secretion. ${ }^{25}$ The cytosolic $\mathrm{Ca}^{2+}$ elevation was a result of an increase in the intracellular ATP levels, which leaded to the closure of $\mathrm{K}_{\text {ATP }}$ channels. Cell depolarization occurred after the closure of $\mathrm{K}_{\mathrm{ATP}}$

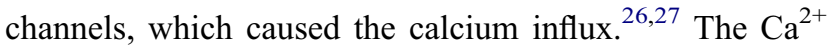
elevation drives GLP-1 secretion by induction of exocytosis. However, it remains to be studied whether the cAMP signal and intracellular calcium ion flow are involved in the SA regulation of GLP-1.

In summary, the present study demonstrated that the SA directly acted on L-cells to induce GLP-1 secretion. The SA activity was observed with an elevation of GLP-1 in the plasma of the lean mice and the culture supernatant of the L-cell line. The SA improved protein expression of $\mathrm{PC} 1 / 3$ and induced activation of ERK1/2. The SA activity in the induction of GLP-1 secretion was blocked by the ERK1/2 inhibitor. The data indicated that SA may induce GLP-1 secretion in L-cells through activation of the ERK1/2 pathway. Nevertheless, the mechanism of ERK1/ 2 activation remains to be explored, and its effects on PC1/ 3 are not clear. The SA is a new bioactive component of Chinese herbal medicines that induces GLP-1 secretion through activation of the ERK1/2 pathway and PC1/3. ${ }^{18-20}$

\section{Conclusion}

The present study provides a direct evidence that SA interacts with L cells for GLP-1 secretion by activation of ERK1/2 and PC1/3. The effects of SA on the GLP-1 secretion is dependent on the ERK1/2 signaling pathway. Therefore, SA is a new drug candidate for the treatment of type 2 diabetes and inhibition of obesity by the induction of GLP-1 secretion.

\section{Acknowledgments}

The project was supported by the National Natural Science Foundation of China (NO. 81874377).

\section{Author Contributions}

All authors contributed to data analysis, drafting or revising the article, gave final approval of the version to be published, and agreed to be accountable for all aspects of the work.

\section{Disclosure}

The authors report no conflicts of interest in this work.

\section{References}

1. Drucker DJ. The biology of incretin hormones. Cell Metab. 2006;3 (3):153-165. doi:10.1016/j.cmet.2006.01.004

2. Toft-Nielsen MB, Madsbad S, Holst JJ. Determinants of the effectiveness of glucagon-like peptide- 1 in type 2 diabetes. $J$ Clin Endocrinol Metab. 2001;86(8):3853-3860. doi:10.1210/jcem.86.8. 7743 
3. Otten J, Ryberg M, Mellberg C, et al. Postprandial levels of GLP-1, GIP and glucagon after 2 years of weight loss with a paleolithic diet: a randomized controlled trial in healthy obese women. Eur $J$ Endocrinol. 2019;180(6):417-427. doi:10.1530/EJE-19-0082

4. Vilsbøll T, Krarup T, Deacon CF, et al. Reduced postprandial concentrations of intact biologically active glucagon-like peptide 1 in type 2 diabetic patients. Diabetes. 2001;50(3):609-613. doi:10.2337/ diabetes.50.3.609

5. Sandoval DA, D'Alessio DA. Physiology of proglucagon peptides: role of glucagon and GLP-1 in health and disease. Physiol Rev. 2015;95(2):513-548. doi:10.1152/physrev.00013.2014

6. D'Alessio DA. What if gut hormones aren't really hormones: DPP-4 inhibition and local action of GLP-1 in the gastrointestinal tract Endocrinology. 2011;152(8):2925-2926. doi:10.1210/en.2011-1385

7. Hjøllund KR, Deacon CF, Holst JJ. Dipeptidyl peptidase-4 inhibition increases portal concentrations of intact glucagon-like peptide-1 (GLP-1) to a greater extent than peripheral concentrations in anaesthetised pigs. Diabetologia. 2011;54(8):2206-2208. doi:10.1007/ s00125-011-2168-7

8. Salehi M, Purnell JQ. The role of glucagon-like peptide-1 in energy homeostasis. Metab Syndr Relat D. 2019;17(4):183-191. doi:10.1089/met.2018.0088

9. Nauck MA, Meier JJ. Incretin hormones: their role in health and disease. Diabetes Obes Metab. 2018;20(suppl 0.1):5-21. doi:10.1111/ dom.13129

10. Rumsey R, Squires PE, Read NW. In vitro effects of sennoside on contractile activity and fluid flow in the perfused large intestine of the rat. Pharmacology. 1993;47(1):32-39. doi:10.1159/000139840

11. Kobayashi M, Yamaguchi T, Odaka T, et al. Regionally differential effects of sennoside A on spontaneous contractions of colon in mice. Basic Clin Pharmacol. 2007;101(2):121-126. doi:10.1111/j.17427843.2007.00088.x

12. Le J, Zhang X, Jia W, et al. Regulation of microbiota-GLP1 axis by sennoside A in diet-induced obese mice. Acta Pharm Sin B. 2019;9 (4):758-768. doi:10.1016/j.apsb.2019.01.014

13. Le J, Jia W, Sun Y. Sennoside A protects mitochondrial structure and function to improve high-fat diet-induced hepatic steatosis by targeting VDAC1. Biochem Bioph Res Co. 2018;500(2):484-489. doi:10.1016/j.bbrc.2018.04.108

14. Li P, Lu Q, Jiang W, et al. Pharmacokinetics and pharmacodynamics of rhubarb anthraquinones extract in normal and disease rats. Biomed Pharmacother. 2017;91:425-435. doi:10.1016/j.biopha.2017.04.109

15. Reimer RA, Darimont C, Gremlich S, et al. A human cellular model for studying the regulation of glucagon-like peptide-1 secretion. Endocrinology. 2001;142(10):4522-4528. doi:10.1210/ endo.142.10.8415
16. Hou W, Yin J, Alimujiang M, et al. Inhibition of mitochondrial complex I improves glucose metabolism independently of AMPK activation. J Cell Mol Med. 2017;22(2):1316-1328. doi:10.1111/ jcmm. 13432

17. Fan H, Chen W, Zhu J, et al. Toosendanin alleviates dextran sulfate sodium-induced colitis by inhibiting M1 macrophage polarization and regulating NLRP3 inflammasome and Nrf2/HO-1 signaling. Int Immunopharmacol. 2019;76:105909. doi:10.1016/j. intimp.2019.105909

18. Tolhurst G, Heffron H, Lam YS, et al. Short-chain fatty acids stimulate glucagon-like peptide-1 secretion via the G-protein-coupled receptor FFAR2. Diabetes. 2012;61(2):364-371. doi:10.2337/db11-1019

19. Kong T, Liu M, Ji B, et al. Role of the extracellular signal-regulated kinase 1/2 signaling pathway in ischemia-reperfusion injury. Front Physiol. 2019;10:1-10. doi:10.3389/fphys.2019.01038

20. Dou $\mathrm{M}, \mathrm{Wu} \mathrm{H}$, Zhu $\mathrm{H}$, et al. Remifentanil preconditioning protects rat cardiomyocytes against hypoxia-reoxygenation injury via $\delta$-opioid receptor mediated activation of PI3K/Akt and ERK pathways. Eur J Pharmacol. 2016;789:395-401. doi:10.1016/j.ejphar.2016.08.002

21. Kim J, Hong S, Wu P, et al. Raf/MEK/ERK can regulate cellular levels of LC3B and SQSTM1/p62 at expression levels. Exp Cell Res. 2014;327(2):340-352. doi:10.1016/j.yexcr.2014.08.001

22. Lim GE, Huang GJ, Flora N, et al. Insulin regulates glucagon-like peptide-1 secretion from the enteroendocrine L cell. Endocrinology. 2009;150(2):580-591. doi:10.1210/en.2008-0726

23. Seljeset S, Siehler S. Receptor-specific regulation of ERK1/2 activation by members of the "free fatty acid receptor" family. J Recept Sig Transd. 2012;32(4):196-201. doi:10.3109/10799893.2012.692118

24. Tian L, Jin T. The incretin hormone GLP-1 and mechanisms underlying its secretion. J Diabetes. 2016;8(6):753-765. doi:10.1111/17530407.12439

25. Kuhre RE, Holst JJ, Kappe C. The regulation of function, growth and survival of GLP-1-producing L-cells. Clin Sci. 2016;130(2):79-91. doi: $10.1042 / \mathrm{CS} 20150154$

26. Mace OJ, Schindler M, Patel S. The regulation of K- and L-cell activity by GLUT2 and the calcium-sensing receptor CasR in rat small intestine. J Physiol. 2012;590(12):2917-2936. doi:10.1113/ jphysiol.2011.223800

27. Reimann F, Habib AM, Tolhurst G, et al. Glucose sensing in L cells: a primary cell study. Cell Metab. 2008;8(6):532-539. doi:10.1016/j. cmet.2008.11.002

\section{Publish your work in this journal}

Diabetes, Metabolic Syndrome and Obesity: Targets and Therapy is an international, peer-reviewed open-access journal committed to the rapid publication of the latest laboratory and clinical findings in the fields of diabetes, metabolic syndrome and obesity research. Original research, review, case reports, hypothesis formation, expert opinion and commentaries are all considered for publication. The manuscript management system is completely online and includes a very quick and fair peer-review system, which is all easy to use. Visit http://www.dovepress.com/testimonials.php to read real quotes from published authors. 